\title{
GREEN SCHOOL PRACTICES: A POTENTIAL TOOL TOWARDS SUSTAINABLE DEVELOPMENT
}

\author{
Prashant Thote ${ }^{* 1} 凹$, Gowri. S 2 \\ ${ }^{* 1,2}$ Gyanodaya Vidya Mandir, India
}

DOI: https://doi.org/10.29121/granthaalayah.v8.i6.2020.423

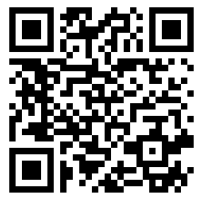

\section{Article Type: Research Article}

Article Citation: Prashant Thote, and Gowri. S. (2020). GREEN SCHOOL PRACTICES: A POTENTIAL TOOL TOWARDS SUSTAINABLE DEVELOPMENT. International Journal of Research GRANTHAALAYAH, 8(6), 63-70. https://doi.org/10.29121/granthaa layah.v8.i6.2020.423

Received Date: 04 May 2020

Accepted Date: 22 June 2020

Keywords:

Environmental Education

Green School

Awareness

Practices

Location

\begin{abstract}
In present century, world faces diverse environmental issues. The school is one the most important place for monitoring, mentoring and promoting sustainable environmental culture in both physical and educational way. Green school programme is an initiative and it is the foundation for environmental education that aims to empower and emancipate students to be the change for our sustainable environment needs by involving fun, joy, and action-oriented learning with responsibility. The level of awareness, practice and understanding of green school practices are investigated among students from senior secondary school. 50 students from senior secondary school participated. Data is collected through 25 items questionnaire. Percentage and t-test are used to analysis the collected data. Result of the study shows that the students understanding and practice of green school practices are very low. Students in the rural residential area have better awareness of green school practices. Recommendations are suggested to include more beginning and integration in chemistry curriculum at senior secondary schools.
\end{abstract}

\section{INTRODUCTION}

Green School Practices are the fundamental initiative which motivates young mind to involve in their environment by allowing them and providing them the opportunity to actively conserve it. It is initiated in the classroom, extended to the school and eventually foster change in the society. Through Green School Programme/activities in a class/school the young mind experience a sense of achievement at being able to have a role in the environmental construction and management policies. The "Green School Practice" is an idea used in school to embrace a meaningful path towards improving environment in school as well as in the community, having lifelong positive impact on lives. The core point is on the process and education: 


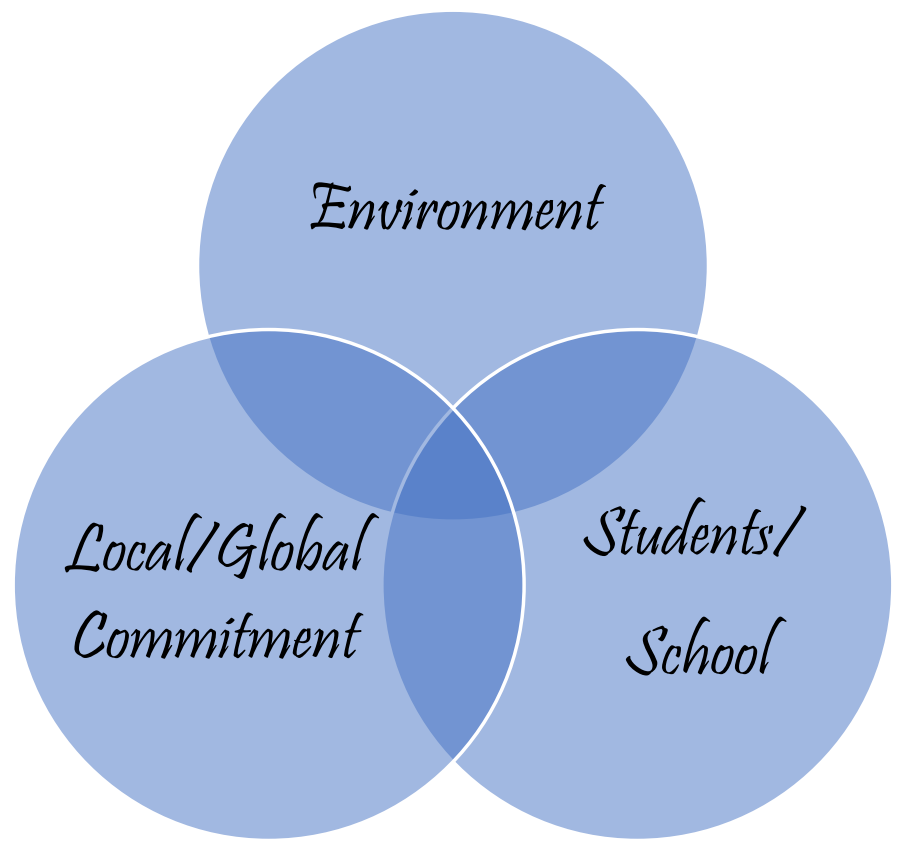

Figure 1: Core Elements

\section{Benefits of Green School Programme: For Students}

- Motivates and empowers students to take action towards economic, social and environmental activities.

- Creates leaders for bringing up change in the society.

- Widens students learning beyond classroom.

- Helps students to develop responsible attitude and commitment.

- Increases student's confidence and motivation.

- Increases student's participation in the sustainable environment action.

- Improves student's knowledge and skills in core subjects and team work.

- Improves student's mental and physical well-being.

\section{For School}

- Fosters school sustainability and bring behavioral change in students, staff and communities.

- Improves positive school environment.

- Integrates school curriculum with sustainable development principle.

- Supports and nurtures intricate value such as care, empathy, compassion and creativity.

- Instills a sense of pride among school staff.

- Encourages the school to be a positive model.

Green school practices actively involve students in sustainable development. It nurtures responsibility and care in the students and the staff. It transfers the school to be sustainable school and integrates learning with the handson experience. Every young mind has the potential to be the change for sustainability that our world needs. It is made possible by connecting students in action- oriented and socially responsible learning. It develops and encourages critical thinking in the students, a better way of doing things. Encourages real life situation and outdoor learning, makes connection and helps in reflection, motivates students to foster and to take responsibility for their future and to make them realize that, they can make difference, develop young leaders of future to instill a sense of responsibility.

\section{Involved Environmental Education Principles}

Ensures the participation and engagement in Teaching-Learning process.

- Empowers students to take informed decisions and actions on real life sustainable issues.

- Encourages students to work together actively and involve their communities in collaborative solution. 
- Cheers up the participant to be aware of cultural practices as an integral part of sustainability issues.

- Supports to examine their assumption, knowledge, experience in order to develop critical thinking and to be open to change.

- Persuades the participant to share inspirational stories, their achievement, failures, and values and to learn from them and support others.

- Reveals the participant to test, share innovative approaches, methodologies and techniques.

- Ensures continuous improvement through monitoring and evaluation is central to this programme.

\section{Advantages of the Green School Practices}

The school that succeeds and do well tie up with education for sustainable development. The Green School Practice provides a simple framework to help and to make sustainability an integrated part of school life. Green school practices help schools to be sustainable and to bring the behavioural changes in school students and to connect students with good habits that they learn in schools.

\section{Green school practices}

- Improve school environment.

- Create intentional connections.

- Help to embed the sustainable development principles into school curriculum.

- Support and nurture intrinsic values.

- Improve well beings of students and staff.

\section{Green School Practices: Integration in School Curriculum}

- The green school practices are more effective when it is integrated and linked to the school syllabus and curriculum wherever possible. The advantages of the integration are:

- The environmental issues become more relevant and alive for the students.

- The school action plan is reinforced and enhanced by the topics/themes.

- Environmental topics which are being taught in the class-room influence the way, the green school operate.

\section{School Performance Indicators}

- The school focuses on behavioural change and performance with reference to the environmental themes in the school curriculum.

- The school selects students as champions and calls them as "Green warrior" - a person responsible for sustainable development education in school.

- Green school practices/activities are integrated in the school curriculum.

- The data is gathered from the environmental reviews and are used in the school curriculum.

- "Green school" theme-based competition, events, projects, practices and international days related to environment are celebrated and conducted as a part of the school curriculum and schedule.

- Teachers are continuously provided with professional development training on the best practices, skills and knowledge to conduct sustainable development activities through their subjects.

- Students of all classes and disciplines get an opportunity to address the environmental issues.

- Students germinate skills, knowledge and attitude through experiential learning and activities based on their curriculum. Students are equipped, empowered, and skilled and develop positive mental attitude to be the change for solving environmental issues in school.

- $\quad$ The core subjects are integrated with the following green school themes. 


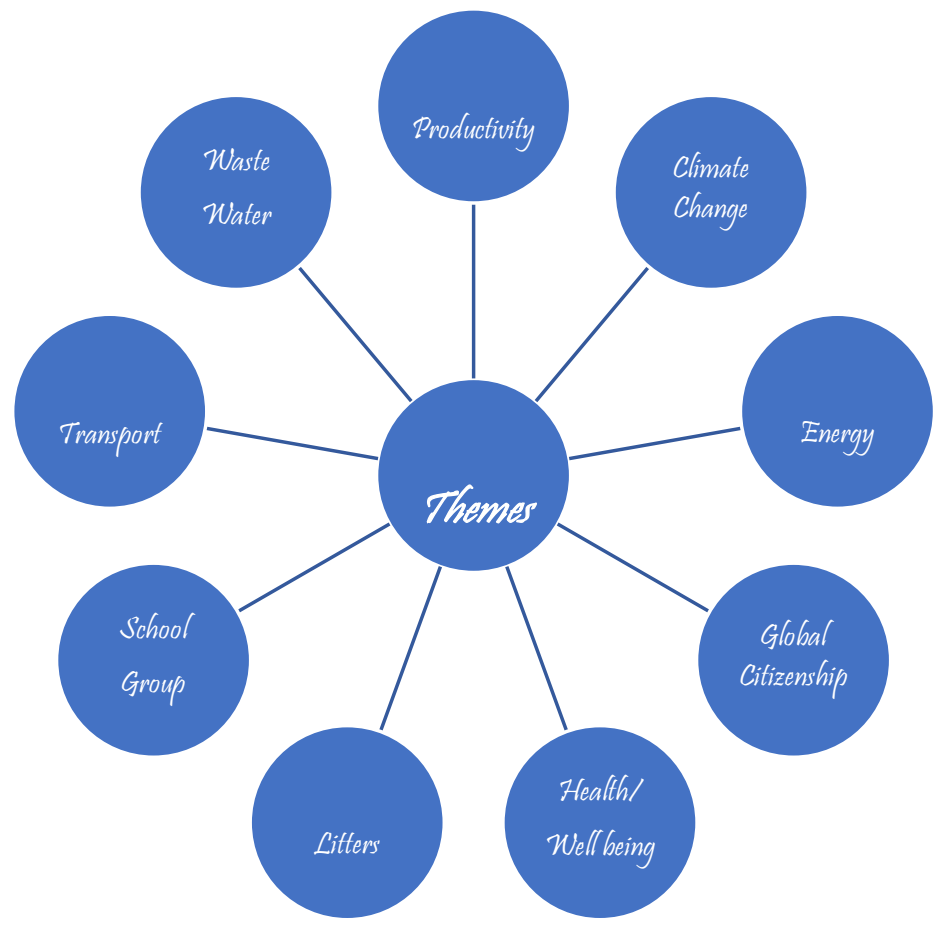

Figure 2: Green School Themes

\section{Gender Equality}

The successful, effective and efficient implementation of green school programmes marches towards the booming of gender equality. It provides all teachers and students' equal rights and an opportunity to participate in the decision making and other activities.

\section{Clean Water and Sanitation}

Students are sensitized towards sustainable use of sanitation and water. The theme on water focuses on the importance of creating awareness about the water, sustainability, reduce the use of water locally/globally.

\section{Affordable Clean Energy}

Green School Practices encourage and initiate teachers and students to save energy and provide innovative and creative solution to reduce the energy consumption in schools, in their homes to improve energy efficiency.

\section{Recent Work and Economic Growth}

Green School Practices foster and promotes deep understanding of sustainability issues among students and develop leadership quality and provide sustainable solutions. The skills and the knowledge are gained by the experiential learning activities, germinate interest on the sustainable issues and broaden the opportunities.

\section{Reduced Inequalities}

Green school practices invoke the adaptation of local culture and practices. It provides access to education for all about sustainable development.

\section{Sustainable Communities}

The integration of waste maintenance in school curriculum fosters responsible behavior and protects culture and natural heritage.

\section{Responsible consumption and protection}

Students are motivated to reflect on their consumption habits, develop ideas, solution for sustainable resources. Knowledge about the reduction and the recycling of waste is provided.

\section{Climate Action}

Green School practices nurture climate change resilience such as rainwater harvesting, soil stabilization, sanitation, food production and waste management.

No Poverty:

Green School Practices is an inclusive programme which accepts all social discrepancies.

\section{Zero hunger}

It promotes improved nutrition, sustainable food production and biodiversity. 


\section{Good Health and Wellbeing}

Green school practices create environmental connectivity with safety and health.

Quality Education

Green School practices are the powerful tool for providing quality education about the sustainable development.

\section{Research Question}

To guide the study the following research questions are designed:

What is the level of green school practices among the secondary school students?

Do the residence locations have any influence on the secondary school students in the level of green practices?

\section{METHODS}

\subsection{RESEARCH DESIGN}

The present study employs descriptive research design.

\subsection{SAMPLE}

Totally 200 secondary school students have participated. Purposive sampling technique is used to draw the sample.

\subsection{TOOL}

The Green School Practices Awareness Questionnaire (GSPQ) is developed to collect the data. It consists of 25 items using the Cron Bran Alpha; the coefficient of the instrument is calculated to be 0.86 at 0.05 levels.

\subsection{DATA ANALYSIS}

Data analysis is done using t-test.

\section{RESULT AND DISCUSSIONS}

Table 1: Level of Green School Practices

\begin{tabular}{|c|c|c|}
\hline Category & $\mathrm{N}$ & $\%$ \\
\hline Knowledge & 140 & 70 \\
\hline Level & 60 & $30 \%$ \\
\hline
\end{tabular}

Table 2: Location of residence and Green school practices

\begin{tabular}{|c|c|c|c|c|c|}
\hline Location of resident & $\mathrm{N}$ & Mean & S. D & de & t \\
\cline { 1 - 4 } Urban & 100 & 72.84 & 7.61 & 198 & 7.28 \\
\cline { 1 - 3 } Rural & 100 & 78.18 & & & \\
\hline
\end{tabular}

Result of the study shows that $60 \%(n=120)$ have knowledge related to green practices in school. The locations of the residence of the students have significant impact on the green school practices. The students residing in the rural area have more knowledge about green practices in school.

\subsection{DISCUSSION}

- Result of the study shows that Green School Practices focus on eco-efficient more than sustainability.

- Sustainability seems to eliminate waste and energy management.

- Green School Practices develop environmental problem solving approach. 
- The integration of sustainable development principle in school system develops high-order thinking skills and problem solving skills. The students look at the problems and come out with the solution.

- To foster and to provide help in enhancing the experiential learning resources, support material, innovative and creative ideas to cope with practical element of the curriculum.

- In developing economy, the green school model programme is cost effective and elicit participation of students and teachers in green facilities, solutions, techniques, approaches, resources, knowledge and skills

- Result of the study reveals that school student's residence has influence on the awareness level of the green practices in school.
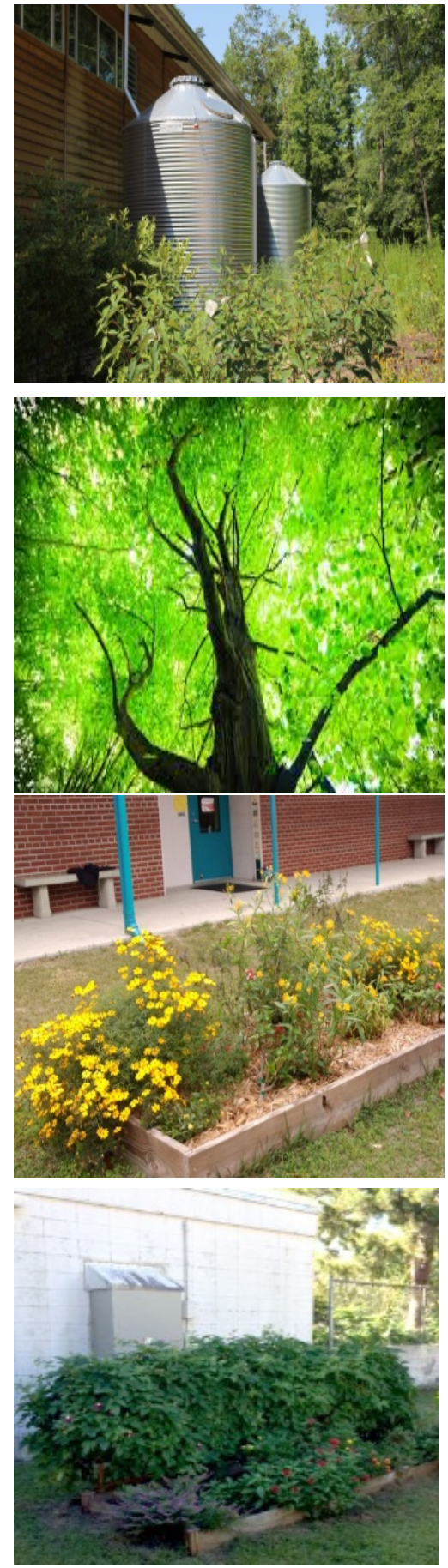
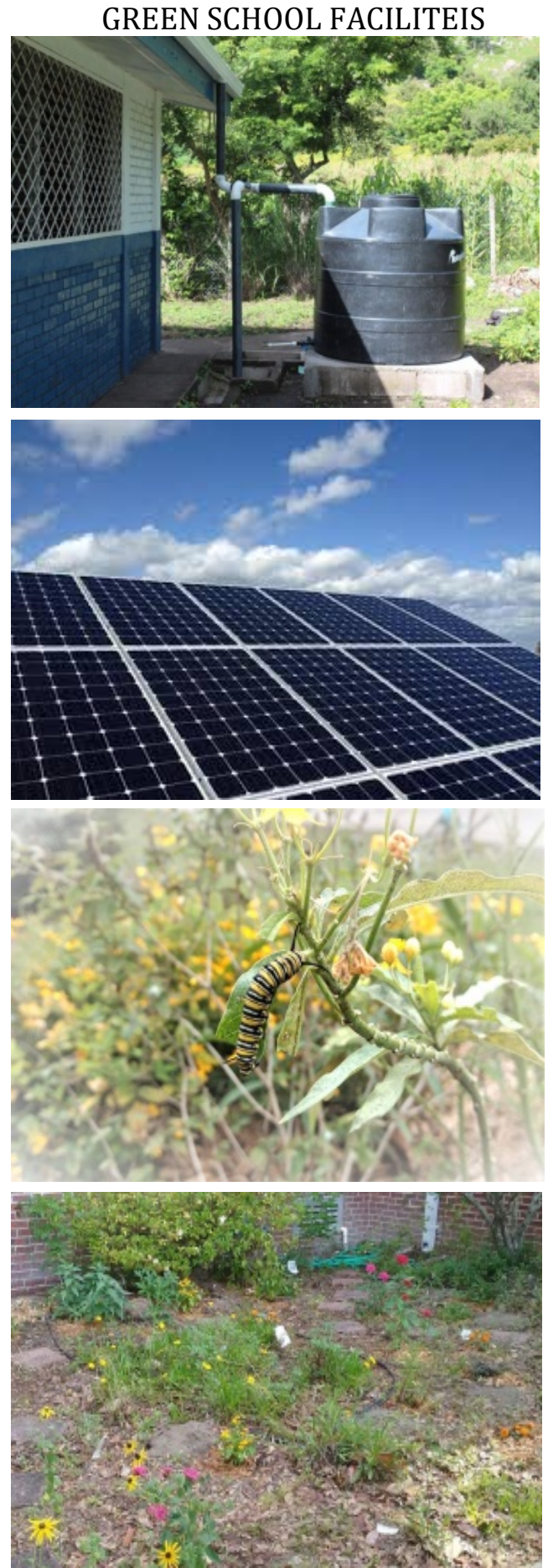
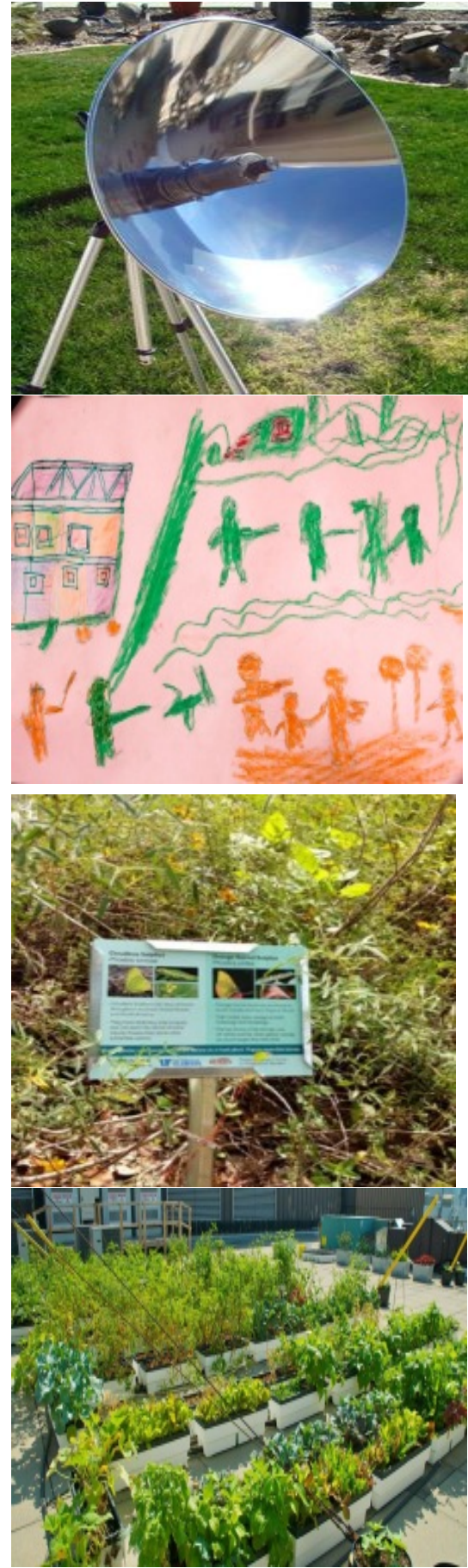


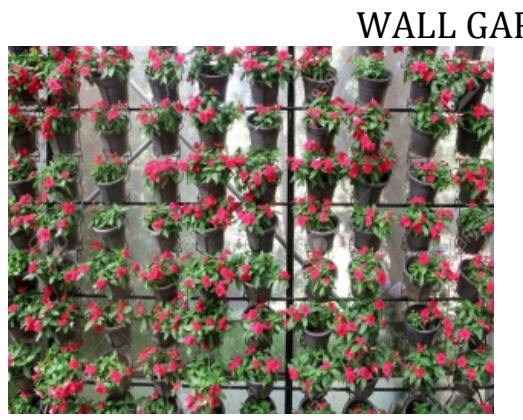

COMPOST

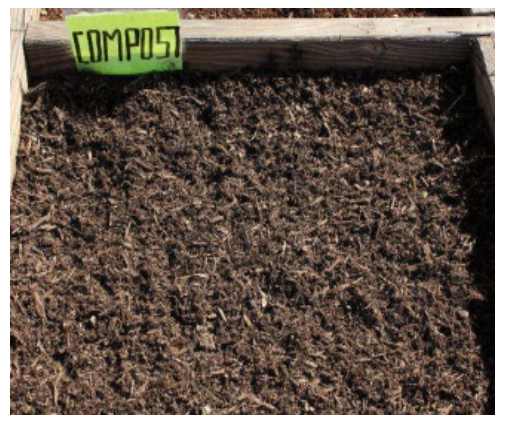

BIOTOPES

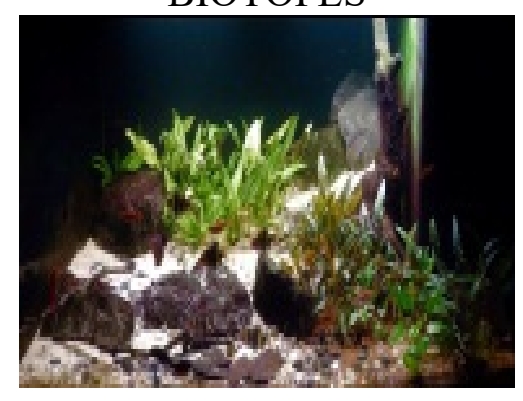

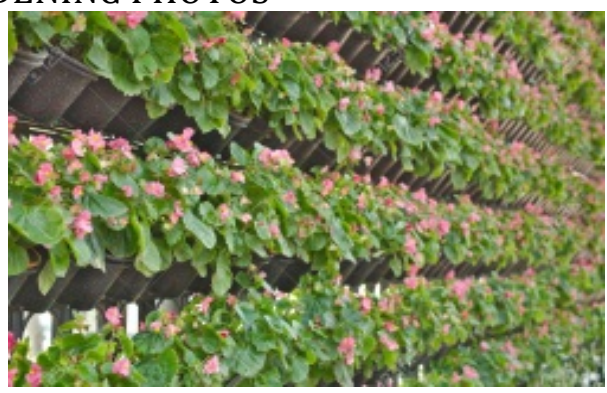

BOTTLE WATERIN PLANTS

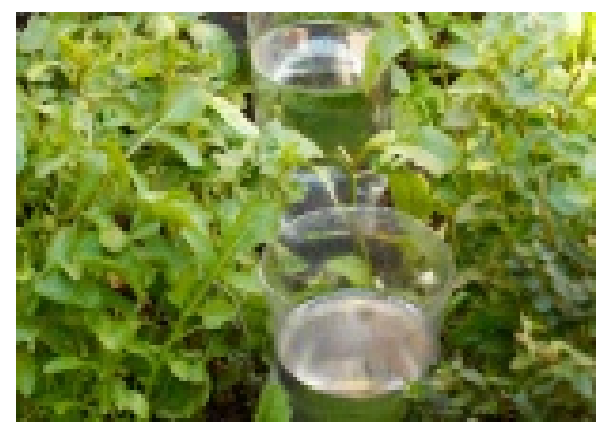

WATER PERMEABLE GROUND PHOTOS

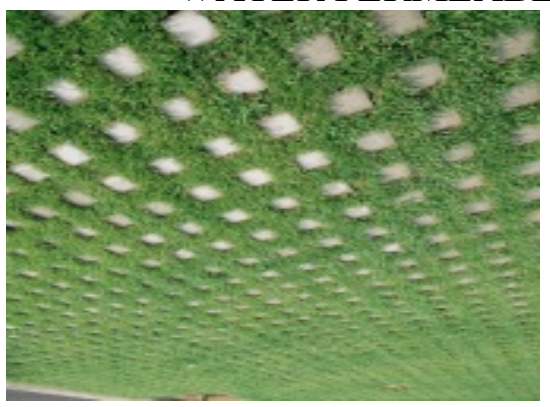

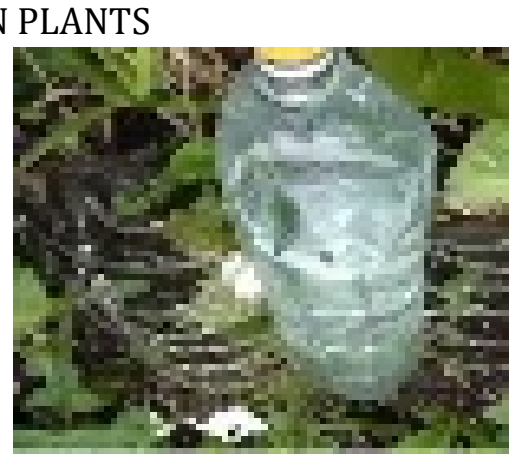
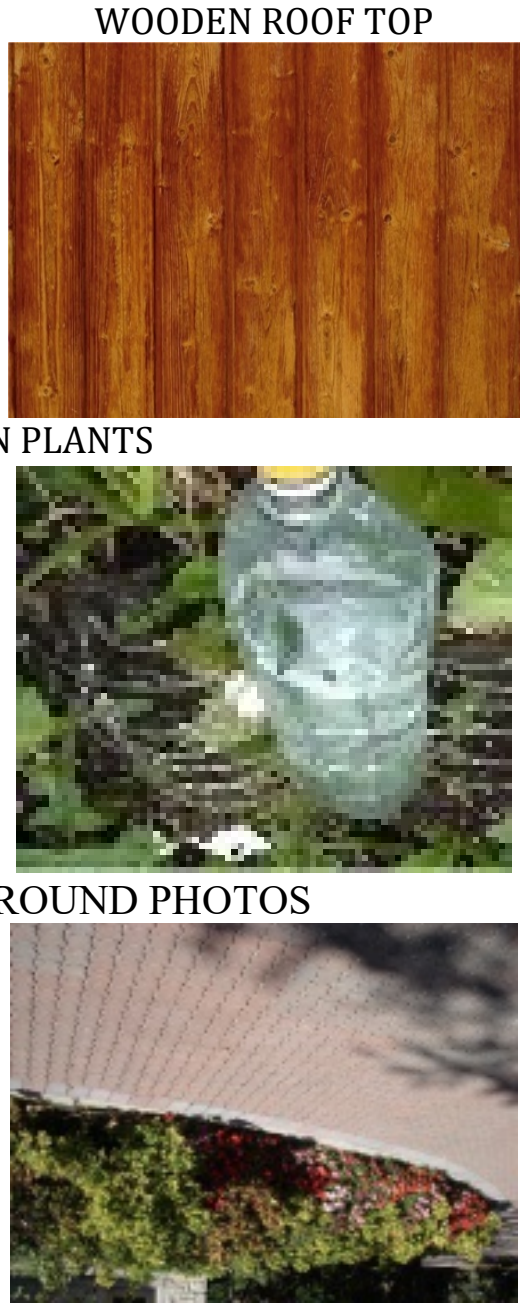

\section{CONCLUSION}

1) Result of the study provides an indication that the senior secondary school students have high awareness related to green school practices in the school.

2) Students residing in urban areas are having low awareness. Students are having easy access to junk food in adolescent age.

3) Students at an adolescent age find pleasure in playing than considering the environmental impact on their activities. Students engage in positive green school programmes. This may be due to exposure in school to experiential learning through green school practices.

\section{SOURCES OF FUNDING}

None.

\section{CONFLICT OF INTEREST}

None.

\section{ACKNOWLEDGMENT}

None. 


\section{REFERENCES}

[1] Prashant Thote, L. Mathew and D.P.S. Rathoure, "Study of Child Friendly School in Central India", Deliberative Research, 0976-1136.

[2] Prashant Thote, "High Order Thinking Skills Questions: A way to Stimulating Learning", International Research Journal Related to Higher Education for All Subjects, 2249-8125.

[3] Prashant Thote, "Study of Experimental Method of Teaching in Senior Secondary School", International Research Journal Related to Higher Education for All Subjects, 2249-8125.

[4] Prashant Thote, "A Study of Practical Task Used in Teaching Chemistry at Senior Secondary Level", International Research Journal, Review of Research, 2249-8125.

[5] Prashant Thote, "Empowering Teaching through Innovative Method: A Case Study", Journal of Research, Extension and Development, 2249-8125. 